\title{
Notas
}

\section{A política brasileira de proteção e de reassentamento de refugiados - breves comentários sobre suas principais características}

JOSÉ H. FISCHEL DE ANDRADE ADRIANA MARCOLINI

\section{Perspectiva histórica}

Embora tivesse se envolvido ativamente no estabelecimento da Liga das Nações, o Brasil retirou-se desta organização em meados dos anos $20^{1}$. Conseqüentemente, o País foi excluído do movimento internacional que teve início em favor da proteção dos refugiados vitimados pelos acontecimentos ocorridos no período entre as duas guerras mundiais. Os refugiados que, porventura, chegaram ao Brasil naquela época receberam o status de imigrantes comuns ${ }^{2}$. Ao final da Segunda Guerra Mundial, vários grupos de refugiados foram reassentados no Brasil - a maioria proveniente da Europa Oriental ${ }^{3}$. Contudo, assim como os grupos anteriores, a legislação brasileira não os reconheceu como refugiados; mais uma vez o País os acolheu como imigrantes comuns.

Em 15 de novembro de 1960, o Brasil depositou junto à ONU instrumento de ratificação da Convenção sobre Refugiados, de $1951^{4}$, havendo, em 7 de abril de 1972, depositado o instrumento de adesão ao Protocolo da Convenção, de $1967^{5}$. Razões de caráter legal e político não permitiram que os refugiados não-europeus pudessem ser protegidos no Brasil, havendo, pois, opção pela alternativa (a) do Artigo $1^{\circ}$, B (1) da Convenção de 1951, segundo a qual apenas refugiados provenientes da Europa tinham o direito de obter proteção no território brasileiro.

O Brasil havia preferido, naquele momento, conceder aos perseguidos nãoeuropeus a condição jurídica de asilado, objeto de uma consolidada prática consuetudinária latino-americana e de vários tratados regionais ${ }^{6}$. Contudo, na década de 70, o Governo brasileiro, não desejoso de ter em seu território latino-americanos com a mesma coloração política daqueles que ele mesmo perseguia, optou por reassentar todos os que aqui chegassem em busca de proteção. Foi com o objetivo de tratar do reassentamento desses refugiados latino-americanos que o Alto 
Comissariado das Nações Unidas para os Refugiados (Acnur) estabeleceu, em $1977^{7}$, um escritório no Rio de Janeiro. Aqueles que chegavam ao Brasil, particularmente os sul-americanos, na esperança de obter o status de refugiado ou de asilado ${ }^{8}$, recebiam apenas um simples visto de turista e eram reassentados em outros países. Desta forma, cerca de 20 mil chilenos, bolivianos, argentinos e uruguaios foram reassentados na Europa, Canadá, Nova Zelândia e Austrália.

Este número significativo de reassentados foi possível graças ao trabalho do escritório do Acnur no Rio de Janeiro e aos valiosos esforços empreendidos pelo ex-arcebispo de São Paulo, Dom Paulo Evaristo Arns. Verdadeiro humanista, o Cardeal Arns demonstrou uma profunda compaixão para com o destino desses latino-americanos que buscavam proteção internacional - atitude refletida no apoio incondicional dado por ele ao Acnur. Em reconhecimento à sua importante contribuição na proteção dos refugiados, em 7 de outubro de 1985 o Cardeal Arns recebeu a Medalha Nansen ${ }^{9}$, que leva o nome do estadista, cientista e explorador do Pólo Norte, o norueguês Fridtjof Nansen (1861-1930), primeiro Alto Comissário para Refugiados da Liga das Nações ${ }^{10}$. Esta honra é conferida pelo Acnur somente àqueles que desenvolvem um trabalho de destaque em prol dos refugiados, e merecem reconhecimento e apoio internacional.

A despeito da limitação geográfica, consubstanciada na alternativa (a) do Artigo 1º, B (1), em 1979 e 1980 o Brasil recebeu, em caráter excepcional, cerca de 150 refugiados vietnamitas (boat people). Tendo sido salvo por navios brasileiros, este grupo foi aceito no País na condição de imigrantes, graças à intervenção do Acnur.

Em 1982, o Governo brasileiro decidiu favoravelmente quanto à presença do Acnur, sem contudo concluir um Acordo-Sede ${ }^{11}$. Após 1984, as autoridades nacionais deixaram de impor limites ao período que os refugiados não-europeus poderiam permanecer no Brasil, enquanto aguardavam as oportunidades de reassentamento oferecidas por outros países. Iniciava-se então uma nova etapa: os que buscavam proteção no Brasil recebiam documentos expedidos pelo Acnur, endossados pelo Departamento de Polícia Federal. Ao adotar este procedimento, as autoridades brasileiras consideravam que os refugiados eram responsabilidade do Acnur e não do governo. Em 1986, com a assistência do Acnur, aproximadamente 200 iranianos (50 famílias), de religião Bahai, foram reassentados no Brasil na condição de imigrantes.

A partir de março de 1989, com a transferência do escritório do Acnur para Brasília, finalmente estreita-se a relação entre este órgão subsidiário da ONU e as autoridades brasileiras. Após a mudança para a capital, o governo declara, com a promulgação do Decreto ${ }^{\circ}$ 98.602, de 19 de dezembro de 1989, sua opção pela alternativa (b) da Convenção de 1951, Artigo 1º, B (1), removendo desta forma a limitação geográfica e abrindo a possibilidade para que refugiados de 
qualquer lugar do mundo pudessem ser reconhecidos como tais no território brasileiro.

O escritório do Acnur em Brasília continuou a avançar de forma significativa: em 3 de dezembro de 1990, o Brasil retirou suas reservas aos artigos 15 e 17 da Convenção de 1951, medida que permitiu aos refugiados gozarem do direito de associação e de exercerem trabalho remunerado ${ }^{12}$. Daí em diante, tentouse estabelecer um procedimento e uma divisão de responsabilidades relativos ao processo de solicitação de refúgio ${ }^{13}$. É interessante observar que o governo brasileiro promoveu essas medidas estimulado apenas por considerações humanitárias, visto que o número de refugiados residentes no território nacional não era nada expressivo - apenas 200 - e não constituía um problema à sociedade.

Esta situação mudou consideravelmente com a retomada da guerra civil em Angola, no fim de 1992. Cerca de 1,2 mil angolanos fugiram para o Brasil - o único país que então lhes concedia visto de turista - e solicitaram a condição jurídica de refugiado. A maioria deles não estava escapando de perseguição individual, mas sim das conseqüências dos conflitos e da violência generalizada. Não se adequavam, portanto, à definição clássica de refugiado, tal como celebrada na Convenção de 1951. Apesar disso, o governo brasileiro aplicou uma definição mais ampla do conceito de refugiado, inspirada pela Declaração de Cartagena, de $1984^{14}$.

Desta forma, os solicitantes angolanos foram reconhecidos como refugiados no Brasil, gozando os mesmos direitos garantidos pela Convenção de 1951. A aplicação desta definição mais ampla do conceito de refugiado também se deu no caso de cerca de 200 solicitantes de refúgio liberianos, que pediram proteção internacional ao Brasil. A partir da guerra iniciada na Libéria em fins de 1989, 70\% dos refugiados reconhecidos como tal no território nacional obtiveram essa condição jurídica graças à aplicação da definição mais abrangente.

\section{A Lei brasileira de refugiados}

Corroborando o seu compromisso com os direitos humanos, em 13 de maio de 1996, o presidente Fernando Henrique Cardoso enviou ao Congresso Nacional Projeto de Lei sobre Refugiados, o qual acompanhava o Plano Nacional de Direitos Humanos ${ }^{15}$. Após ter sido aprovado pela Câmara dos Deputados e pelo Senado Federal, o projeto, elaborado com a colaboração técnica do Acnur, foi transformado na Lei 9.474, de 22 de julho de 1997. Esta célere aprovação, que contou com o apoio particular da Comissão de Direitos Humanos da Câmara dos Deputados, da Igreja católica e da vice-Presidência da República, não deve passar despercebida.

A Lei 9.474, que define o estatuto dos refugiados no Brasil, é a primeira legislação abrangente dedicada a este tema na América Latina. Dois aspectos que 
ela possui merecem atenção especial ${ }^{16}$. O primeiro diz respeito à definição do conceito de refugiado. Além de reproduzir a definição clássica da Convenção de 1951, no seu Artigo 1 $^{\circ}$ (III), a Lei 9.474 afirma que um indivíduo deve ser reconhecido como refugiado se "devido a grave e generalizada violação de direitos humanos, é obrigado a deixar seu país de nacionalidade para buscar refúgio em outro país”. Esta definição abrangente é importante, sobretudo quando são consideradas as causas dos recentes deslocamentos forçados ao redor do mundo. Além disso, a definição vai ao encontro da prática adotada pelo Governo brasileiro desde o início da década de $1990^{17}$.

Outro aspecto digno de nota é a criação do Comitê Nacional para os Refugiados (Conare), órgão formado por sete membros, que representam, respectivamente, os ministérios da Justiça, Relações Exteriores, Trabalho, Saúde, Educação e Esporte, o Departamento de Polícia Federal, e a Caritas, organização não-governamental da Igreja católica parceira do Acnur no Brasil, que oferece assistência e programas de integração aos refugiados. O Acnur está sempre autorizado a participar das reuniões do Conare, com voz, mas sem direito a voto.

Duas competências do Conare devem ser sublinhadas. A primeira diz respeito ao processo de elegibilidade, que é responsabilidade total das autoridades nacionais. Isto significa que o governo usa sua própria legislação e seu questionário ${ }^{18}$ para decidir sobre uma solicitação de refúgio, sendo as entrevistas realizadas por um funcionário do Conare. A partir dos questionários, o entrevistador elabora pareceres sobre a pertinência de se conceder, ou não, a condição jurídica de refugiado. Esses pareceres, por sua vez, são apresentados nas sessões do Conare, nas quais se decide pela aceitação, ou recusa, das solicitações ${ }^{19}$. No caso de recusa, a lei prevê que o solicitante pode recorrer da decisão. O reconhecimento da condição de refugiado não é mais publicado no Diário Oficial, como ocorria quando o Acnur era responsável por todo o processo decisório ${ }^{20}$; atualmente o solicitante é notificado pessoalmente.

O segundo papel cumprido pelo Conare, digno de destaque, diz respeito à promoção e coordenação de políticas e ações necessárias para uma eficiente proteção e assistência aos refugiados, além do apoio legal. Este papel facilita a implementação das soluções duradouras para os desafios a serem enfrentados por um refugiado; a saber, repatriação voluntária, integração local e reassentamento soluções essas também abordadas na Lei de Refugiados.

\section{Os refugiados no Brasil, hoje}

Cerca de 2,7 mil famílias de refugiados (às vezes o núcleo familiar é formado por apenas um só indivíduo), de 47 nacionalidades, vivem atualmente no Brasil. A maioria delas é originária da África, notadamente de Angola (aproximadamente 1,6 mil). Entre as outras nacionalidades africanas, há cerca de 250 liberianos, 160 
congoleses e 130 serra-leoneses. Aproximadamente 70 iraquianos e 100 cidadãos provenientes da ex-Iugoslávia também foram reconhecidos como refugiados. Entre os sul-americanos, há cerca de 10 colombianos, mas o acirramento dos conflitos entre os guerrilheiros da esquerda, seus rivais paramilitares da direita e a Força Pública deve levar este número a crescer. Estimativas de fins de 2001 revelam que cerca de 2 milhões de colombianos deixaram suas próprias casas nas últimas décadas em decorrência dos conflitos no país.

Uma vez reconhecida a condição jurídica de refugiado no Brasil, a pessoa recebe uma carteira de identidade, emitida pela Polícia Federal, tem direito à assistência médica pública, e está autorizado a estudar e a trabalhar. Graças às estratégias desenvolvidas para integrar os refugiados na sociedade local, a maioria deles beneficia-se de programas sociais públicos e privados. Com base numa análise caso-a-caso, o refugiado pode receber ajuda financeira, concedida pelo Acnur, por um período de tempo determinado. Esta ajuda, equivalente a um salário mínimo, é distribuída pelas Cáritas Arquidiocesanas do Rio de Janeiro e de São Paulo.

Apesar das dificuldades econômicas, o Brasil tem capacidade para receber e oferecer oportunidades àqueles que desejam aqui permanecer. A sociedade brasileira, multi-étnica, é o resultado de uma combinação de pessoas com diferentes ascendências nacionais, que a torna aberta e tolerante em relação à chegada de refugiados e imigrantes em geral. Além disso, durante a ditadura militar (19641985), parte da elite brasileira (intelectuais, professores, políticos) foi exilada, sendo, portanto, simpática à necessidade de se receber e proteger aqueles que fogem de perseguição, e à transformação de nosso território num espaço humanitário ${ }^{21}$.

O tema "refugiados” adquiriu importância ainda maior, no Brasil, após o retorno à democracia, em 1985, e a adoção de uma nova Constituição, em 1988. A Carta Magna, em seu Artigo 4 (II), reconheceu a prevalência dos direitos humanos como o princípio norteador das relações internacionais do Brasil, abrindo caminho para uma abordagem diferente da proteção do ser humano. As inovações constitucionais, a necessidade de o Estado brasileiro reorganizar sua agenda externa, o objetivo de compor uma imagem mais positiva no contexto internacional e o aceite do Brasil para com a idéia contemporânea de globalização dos direitos humanos $^{22}$ facilitaram a inserção da questão dos refugiados na agenda nacional.

Graças ao fortalecimento da democracia, observa-se uma preocupação com a proteção dos direitos humanos no Brasil. A nova situação favorece iniciativas como a de Passo Fundo, no Rio Grande do Sul, que, em 1988, recebeu um escritor cubano perseguido, tornando-se o primeiro município das Américas a aderir à Rede de Cidades para Refugiados. Na ocasião, o Governo brasileiro garantiu a condição jurídica de refugiado para um escritor, que passou a lecionar na Universidade de Passo Fundo, instituição com cerca de 10 mil estudantes. Lançada em 1994 pelo Parlamento Internacional de Escritores, com o apoio da União Européia, esta rede tem como objetivo proteger e apoiar escritores perseguidos em seus próprios países. 
Amsterdã, Estrasburgo, Barcelona e Porto estão entre as cidades que participam do programa.

\section{Uma nova iniciativa: o programa de reassentamento}

À medida que o regime democrático no Brasil se consolida, a implementação da Lei sobre Refugiados também avança. O programa brasileiro de reassentamento está fundamentado nos artigos 45 e 46 da Lei 9.474/97, que salientam, respectivamente, o caráter voluntário do reassentamento e a necessidade de planejamento, coordenação e determinação de responsabilidades de todas as partes envolvidas neste processo. O Governo brasileiro endossou o programa de reassentamento em 1999, inspirado por razões humanitárias.

A seção de Reassentamento do Acnur, localizada na sua sede em Genebra, prioriza, no momento, a consolidação e o apoio aos programas lançados nos países escolhidos pela organização para serem os novos centros de reassentamento: Argentina, Brasil, Chile, Benin, Burkina Faso, Irlanda, Islândia e Espanha. Em novembro de 2000, um consultor do Acnur, especialista em reassentamento, começou a trabalhar no Escritório Regional para o Sul da América do Sul, em Buenos Aires. Suas tarefas incluem o planejamento e a implementação, em estreita parceria com os governos e organizações não-governamentais do Brasil, Chile e Argentina, de programas de reassentamento nesses países.

Em março de 2001, uma missão do Acnur visitou quatro cidades brasileiras, escolhidas pelo Ministério da Justiça para sediar os projetos-piloto de reassentamento a serem coordenados pelo Conare. A decisão de se fazer uma visita prévia às cidades derivou da preocupação das autoridades brasileiras em assegurar que os refugiados reassentados sejam bem recebidos e tenham uma boa integração nas comunidades locais. Nos contatos com representantes da sociedade civil, como as Câmaras de Comércio e Indústria, explicou-se a iniciativa de reassentamento e se solicitou o apoio local - sempre com uma boa receptividade. Em agosto de 2001 realizou-se, no Rio de Janeiro, um seminário, com a participação do Acnur, de ONGs e de autoridades do Governo federal, oportunidade na qual concluiu-se o planejamento do programa de reassentamento.

Com base em critérios como tamanho, atividade econômica e origem étnica da população, o Ministério da Justiça escolheu as seguintes cidades para a fase inicial do programa de reassentamento: Porto Alegre (RS), Mogi das Cruzes (SP), Santa Maria Madalena (RJ) e Natal (RN). Autoridades locais e organizações nãogovernamentais, selecionadas pelo Ministério da Justiça, comprometeram-se em apoiar a iniciativa.

Além disso, estabeleceu-se que o projeto-piloto será desenvolvido em pequena escala, a fim de evitar a possibilidade de se criar um peso indevido às comunidades locais e/ou aos serviços públicos oferecidos pelos municípios. Daí a 
decisão de que as quatro cidades escolhidas recebam, no máximo, 25 refugiados cada uma. Na fase inicial, as autoridades brasileiras planejam dar acolhida a cerca de 100 refugiados por ano. O programa de reassentamento não fixa nenhuma quota por nacionalidade, mas ficou estabelecido que o primeiro grupo será formado por iranianos, botswanianos e afegãos. A chegada destes últimos está prevista para março de 2002.

\section{Conclusão}

Outrora refúgio temporário àqueles que escapavam de perseguição em países vizinhos, o Brasil passou a receber refugiados de outros continentes e a ser uma opção para os que necessitam ser reassentados. Esta nova condição é resultado do intenso trabalho desenvolvido pelo Acnur na região, durante os anos 90, e da consolidação do processo democrático por que passa o País, desde a queda da ditadura, em meados dos anos 80. O Programa Nacional de Direitos Humanos, elaborado na primeira gestão do presidente Fernando Henrique Cardoso, insere-se neste contexto, assim como sua atualização, concluída no início de 2002.

A lei brasileira sobre refugiados é um instrumento legal moderno e oportuno. É coerente e caminha pari passu tanto com as práticas implementadas pelas autoridades nacionais, como com as normas vigentes em relação aos refugiados nos planos internacional e regional. Ademais, pode e deve servir como ponto de partida para harmonizar as políticas e os instrumentos legais para a proteção dos refugiados na América Latina ${ }^{23}$ e como exemplo para países de outros continentes ${ }^{24}$.

As disposições para o reassentamento, tal como definidas na Lei 9.474/97, são a base para uma nova etapa na proteção dos refugiados na América do Sul em geral, e no Brasil em particular. O projeto-piloto para o reassentamento de refugiados deve reafirmar a hospitalidade brasileira - que, a partir de agora, será oferecida também a vítimas de migração forçada que não puderam obter a proteção necessária no primeiro país de refúgio.

\section{Notas}

1 Sobre a saída do Brasil da Liga das Nações, v., em geral, P. Calogeras, “O Brasil e a Sociedade das Nações”, Separata do n ${ }^{\circ} 6$ de $O$ Commentário, São Paulo, 30 de junho de 1926, 58p.; J.C. de Macedo Soares, O Brasil e a Sociedade das Nações, Paris, Pedone, 1927, 345p.; e E.V. Garcia, O Brasil e a Liga das Nações (1919-1926), Porto Alegre/Brasília, Ed. da Ufrgs/Funag, 2000, 167p.; e, sobre os aspectos jurídicos, C. Bevilaqua, “[Parecer] Saída do Brasil da Sociedade das Nações e da Corte Permanente de Justiça Internacional (21.06.26)”, in Pareceres dos Consultores Jurídicos do MRE (1913-1934), Rio de Janeiro, Seção de Publicações/MRE, 1962, p. 343-344; id. ibid., in A.P.C. de Medeiros (org.), Pareceres dos Consultores Jurídicos do Itamaraty (1913-1934), vol. II, Brasília, Senado Federal, 2000, p. 343-344. 
2 V. correspondência do consultor jurídico, Clóvis Bevilaqua, ao Secretário Geral do Ministério das Relações Exteriores, Ministro Nabuco, datada de 12 de março de 1934, na qual se afirma que "nenhum interesse tem o Brasil em adherir a uma Convenção applicavel aos refugiados russos, armenios e assemelhados (...). Os estrangeiros, que procurarem o Brasil, não sendo indesejáveis, terão o tratamento, que a nossa hospitalidade concede, e o gozo dos direitos que as nossas leis lhes attribuem. Não poderão ser submettidos a regimen especial, como estabelece a Convenção, a que me refiro” [I.D. F./12/3/34 - Arquivo Histórico do Palácio do Itamaraty, Rio de Janeiro]. V., a esse respeito, H. Lobo, A Organização Internacional para os Refugiados e o Brasil, Rio de Janeiro, MRE, 1948, 13p., A.H. Neiva, Deslocados de Guerra - a verdade sobre sua seleção, Rio de Janeiro, s/e, 1949, 301p.

4 Para o instrumento de promulgação, v. Decreto ${ }^{0}$ 50.215, de 28 de janeiro de 1961.

5 Para o instrumento de promulgação, v. Decreto $n^{\circ} 70.946$, de 7 de agosto de 1972.

$6 \quad$ E.g. Tratado de Montevidéu sobre Direito Internacional Penal, de 1889; Convenção de Havana sobre Asilo, de 1928; Convenção de Montevidéu sobre Asilo Político, de 1933; Tratado de Montevidéu sobre Direito Penal Internacional, de 1940; e as Convenções de Caracas sobre Asilo Diplomático e sobre Asilo Territorial, ambas de 1954. Para os respectivos textos, v. Collection of International Documents, Geneva, UNHCR, 1990, p. 236-273.

7 Para os detalhes do estabelecimento do escritório do ACNUR no Rio de Janeiro, onde teve o fundamental apoio da Igreja Católica, v. C. Mendes \& M. Bandeira, Comissão Brasileira Justiça e Paz, 1969-1995, Empenho e Memória, Rio de Janeiro, Educam, 1996, p. 114-118. Para algumas das diferenças entre as condições jurídicas de "asilado" e de “refugiado”, v. J.H. Fischel de Andrade, "Regionalización y Armonización del Derecho de Refugiados: una perspectiva Latinoamericana”, in Derechos Humanos y Refugiados en las Américas: lecturas seleccionadas, San José, ACNUR/IIDH, 2001, p. 88-91.

9 V. P.E. Arns, Da Esperança à Utopia: testemunho de uma vida, Rio de Janeiro, Sextante, 2001, p. 417-418.

10 Para o desenvolvimento histórico do Direito Internacional dos Refugiados, v. J.H. Fischel de Andrade, Direito Internacional dos Refugiados: evolução histórica (1921-1952), Rio de Janeiro, Ed. Renovar, 1996, 213p.

11 Em correspondência datada de 20 de julho de 1982, n 132, o Representante Permanente adjunto junto às Organizações Internacionais, em Genebra, Emb. Alvaro Gurgel de Alencar, informou a Poul Hartling, Alto Comissário das Nações Unidas para os Refugiados, que "Le Gouvernement brésilien octroiera au bureau les mêmes privilèges et immunités concédées aux agences des Nations Unies, conformément aux termes de la Convention sur les privilèges et immunités”. [Divisão de Atos Internacionais, Itamaraty].

12 Curiosamente, tanto o Decreto $n^{\circ} 70.946 / 72$ quanto o Decreto $n^{\circ} 98.602 / 89$ omitiram a retirada, pelo Brasil, das reservas aos artigos 15 e 17 da Convenção de 1951, ocorrida em 7 de abril de 1972, quando do depósito da Carta de Adesão ao Protocolo de 1967. As referidas reservas ficaram valendo, portanto, no ordenamento jurídico interno, de 1972 até 3 de dezembro de 1990, quando foi promulgado o Decreto n ${ }^{\circ}$ 99.757, que, ao corrigir essa omissão, estipulou, no plano interno, o comprometimento integral com os dispositivos da Convenção de 1951.

13 V. a Portaria Interministerial n ${ }^{\circ} 394$, de 29 de julho de 1991, que visa a regulamentar a condição jurídica do refugiado no Brasil e a Instrução de Serviço 1/91/DPMAF, de 4 de setembro de 1991, que serve de orientação para a Polícia Federal cumprir a Portaria 394/91.

14 A Declaração de Cartagena é o resultado de um colóquio acadêmico patrocinado pela Universidade de Cartagena, o Centro Regional para Estudos do Terceiro Mundo e o ACNUR, sob os auspícios do Governo colombiano. Para a compilação dos instrumentos e apresentações feitas durante o evento, v. La Protección Internacional de los Refugiados en América Central, México y Panamá: Problemas Jurídicos y Humanitários (Colóquio de Cartagena de Índias, 19-22.XI.84), Bogotá, ACNUR/Centro Regional de Estudios del Tercer Mundo/Universidad Nacional de 
Colombia, 1986, 347p. Nada obstante cuidar-se de uma declaração, não redigida para ter força jurídica vinculante, há quem defenda a transformação da Declaração de Cartagena em fonte do Direito; v., a esse respeito, H. Gros Espiell, "La Declaración de Cartagena como Fuente del Derecho Internacional de los Refugiados en América Latina”, in 10 Años de la Declaración de Cartagena sobre Refugiados (Colóquio de San José, 5-7.XII.94), San José, IIDH/ACNUR, 1995, p. 453-470.

15 Constava no Plano Nacional de Direitos Humanos, como proposta de ação governamental a ser executada a curto prazo, "Propor projeto de lei estabelecendo o estatuto dos refugiados".

Cf. J.H. Fischel de Andrade, “O Refugiado à Luz do Direito Internacional e do Direito Brasileiro”, in O Advogado: desafios e perspectivas no contexto das relações internacionais, Brasília, Conselho Federal da OAB, 1997, p. 149-164.

17 O Projeto de Lei enviado pela Presidência da República ao Congresso não incluía a definição ampla de refugiado, a qual só foi inserida, posteriormente, pelo seu relator na Comissão de Constituição, Justiça e Redação da Câmara dos Deputados, o então deputado Aloysio Nunes Ferreira Filho; cf. J.H. Fischel de Andrade, “O Brasil e a Proteção de Refugiados: a discussão tem início no Congresso Nacional”, 16 Pensando o Brasil (1996), p. 7-12.

18 V. Resolução Normativa n ${ }^{\circ}$ 2, de 27 de outubro de 1998, que adota o modelo de questionário para solicitação de refúgio.

19 No processo decisório, o Conare utiliza, como subsídio, estudos sobre a situação objetiva nos países de origem dos solicitantes de refúgio, os quais são preparados pelo Instituto Brasileiro de Relações Internacionais (Ibri), no marco de um convênio com o Acnur; cf. A. Verwey et al., “A percepção brasileira dos refugiados”, 43 (1) Revista Brasileira de Política Internacional (2000), p. 185.

20 Até o advento da Lei 9.474/97 e o estabelecimento do Conare, em 1998, o ACNUR responsabilizava-se por praticamente todo o processo de determinação da condição de refugiado (recepção, formulário, entrevista, assistência, parecer de elegibilidade), posto que o governo se limitava a analisar as recomendações positivas que recebia do Escritório do Encarregado de Missão do Acnur. Sobre os aspectos jurídicos do procedimento de determinação da condição de refugiado, v. J.H. Fischel de Andrade, “De la Determinación de la Condición de Refugiado”, in J. Irigoin Barrenne (comp.), Derecho de Refugiados en el Sur de América Latina: armonización legislativa y de procedimiento (Seminário de Buenos Aires, 22-24.VIII.1995), Santiago, ACNUR/Instituto de Estudios Internacionales/Universidad de Chile (Colección Estudios Internacionales), 1996, p. 70-80.

21 Cf. G.L. da Cunha \& G.A. de Almeida, "Exemplo de globalização solidária”, Folha de São Paulo, 11 de janeiro de 2002, p. A-3 (tendências/debates).

22 V. F. Piovesan, Temas de Direitos Humanos, São Paulo, Max Limonad, 1998, p. 33-34.

23 V., a esse propósito, J.H. Fischel de Andrade, "Derecho de los Refugiados en América Latina: reflexiones sobre su futuro”, in S. Namihas (coord.), Derecho Internacional de los Refugiados, Lima, Pontificia Universidad Católica del Perú/Instituto de Estudios Internacionales, 2001, p. 191-225; e ibid., "Regional Policy Approaches and Harmonization: A Latin American Perspective”, 10(3) International Journal of Refugee Law (1998), p. 389-409.

24 Cf. P.R.C.T. da Fontoura \& R. Goidanich, “O Brasil e a Questão dos Refugiados”, 7 (1) Política Externa (1998), p. 170. 